\title{
有限要素法による二次元交流磁界解析のための アダプティブ分割法
}

\author{
正 員 齊 藤 義 則 (三菱電機コントロールソフトウェア) \\ 非会員上 田 泰 子 (三菱電機) \\ 正員 小 倉 新 三 (三菱電機)
}

\section{Adaptive Mesh Generation for Two Dimensional AC Magnetic Field Analysis in Finite Element Method}

Yoshinori Saito, Member (Mitsubishi Electric Control Software Corporation), Yasuko Ueda, Non-member, Shinzou Ogura, Member (Mitsubishi Electric Corporation)

Fine mesh divisions are essential to obtain accurate solutions of two dimensional AC magnetic field analysis. But it requires the technical know-how to find fine mesh divisions and moreover it is complicated to divide the analysis domain. So we have developed the adaptive mesh generator using equalization of energy variation of every element and applying the technical know-how to divide the conductor or magnetic material under consideration of the skin effect by the eddy current. And we have applied this adaptive mesh generator to the loss analysis of the infinite copper-plane, and we have obtained accurate solutions.

キーワード：有限要素法, 自動分割, 磁界解析

\section{1. まえがき}

電気機器の開発設計において有限要素法による磁界 解析は非常に有用であり，広く用いられている。しか しながら，この有限要素法に抢いては解析領域を三角 形や四角形などの要素に分割しなければならず，この ために多くの労力を必要とする。また，分割の細かさ が解析結果の精度に影響するため, 磁界解析特有の分 割のノウハウにより要素配分の最適な粗密を与えてゃ らなければならない。従って, 初心者が簡単に解析を 行うことは困難であり, ベテランでもデータの入力ミ スなどの間違いを起こしやすい。

そこで，これらを解決するため，今までに幾つかの 自動分割プログラムが研究，開発されてきた。例え ば,グラフィックスを用いて形状や分割の粗密を会話 形で入力するものや(1)，解析領域を幾何学的な分割で 解析した後, 場の沉関数が最小になるように節点の追
加，削除を行い再分割するもの ${ }^{(2)(3)}$ がある。

今回, 著者らは各有限要素の単位時間あたりのエネ ルギー変化（以下，エネルギー変化と記す）を均一に するエネルギー均一化分割法を用い，これに導体や磁 性体の渦電流による表皮効果を考慮した分割のノウ八 ウを取入れ，解析精度の向上を図った磁界解析用アダ プティブ分割プログラムを開発した ${ }^{(4)}$ 。

本諭文では，このプログラムに扔ける分割方法と， これを無限平板の損失解析に適用し詥差を検討した結 果，捛よび実機への適用例について述べる。

\section{2. エネルギー均一化分割法}

よく知られているように, 有限要素法による磁界解 析では，磁束の集中するところほど細かく分割するこ とが計算精度を良くする一つの条件となる。そこで, このプログラムでは幾何学的分割に各要素のエネルギ 一変化が均一になるように節点の追加, 削除を行うこ 


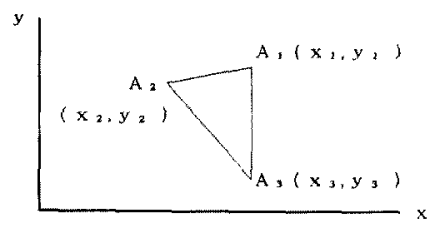

図 1 一次三角形要素

Fig. 1. Triangular element.

とにより，前記の条件を満たす分割を行う。

〈2・1〉要素のエネルギ一变化 要素は一次三角 形要素とし，要素内の交流磁界による磁気べクトルポ テンシャルの $Z$ 方向成分を $A$ (以下，ポテンシャル $A$ と記すと扔いて次式のように仮定する。ただし， ここでポテンシャル $A$ は，交流磁界中でベクトルポ テンシャルが時間的に正弦波状に変化すると仮定し，

複素数表示したものを表す。

$$
A=a_{0}+a_{1} x+a_{2} y
$$

ここに， $a_{0}, a_{1}, a_{2}:$ 要素ごとに異なる定数 この(1)式に要素の各頂点の座標およびポテンシャル 值 $\left(A_{1}, A_{2}, A_{3}\right)$ を代入し， $a_{0}, a_{1}, a_{2}$ について解くと $a_{0}, a_{1}, a_{2}$ は次式のように求まる。

$$
\left(\begin{array}{l}
a_{0} \\
a_{1} \\
a_{2}
\end{array}\right)=\left(\begin{array}{lll}
1 & x_{1} & y_{1} \\
1 & x_{2} & y_{2} \\
1 & x_{3} & y_{3}
\end{array}\right)^{-1}\left(\begin{array}{l}
A_{1} \\
A_{2} \\
A_{3}
\end{array}\right)
$$

一方，磁界のエネルギ一変化は次式で表される。

$$
W_{1}=\frac{f}{\mu} \iint\left\{\left(\frac{\partial A}{\partial x}\right)^{2}+\left(\frac{\partial A}{\partial y}\right)^{2}\right\} d S
$$

ここに，f:周波数， $\mu$ : 透磁率

侹って，(1)，(2)式を用いると(3)式の磁界エネル ギー変化は次式のようになる。

$$
\begin{aligned}
W_{\mathrm{I}} & =\frac{f}{\mu} \iint\left\{\left(a_{1}\right)^{2}+\left(a_{2}\right)^{2}\right\} d S \\
& =\frac{f}{\mu} \iint\left\{\left(a_{0} a_{1} a_{2}\right)\left(\begin{array}{lll}
0 & 0 & 0 \\
0 & 1 & 0 \\
0 & 0 & 1
\end{array}\right)\left(\begin{array}{l}
a_{0} \\
a_{1} \\
a_{2}
\end{array}\right)\right\} d S \\
& =\frac{f}{\mu} \iint\left\{\left(\begin{array}{lll}
A_{1} & A_{2} & \left.A_{3}\right) \\
& & \left.\left(\begin{array}{lll}
0 & 0 & 0 \\
0 & 1 & 0 \\
0 & 0 & 1
\end{array}\right)\left(\begin{array}{lll}
1 & x_{1} & y_{1} \\
1 & x_{2} & y_{2} \\
1 & x_{3} & y_{3}
\end{array}\right)^{-1}\right]^{T} \\
1 & x_{2} & y_{2} \\
1 & x_{3} & y_{3}
\end{array}\right)^{-1}\left(\begin{array}{l}
A_{1} \\
A_{2} \\
A_{3}
\end{array}\right)\right\} d S \ldots .
\end{aligned}
$$

次に，導体の損失は次式で表される。

$$
W_{2}=\frac{1}{2 \sigma} \iint J J^{*} d S
$$

ここに, $J$ : 電流密度, * : 複素共役, $\sigma$ : 導電率

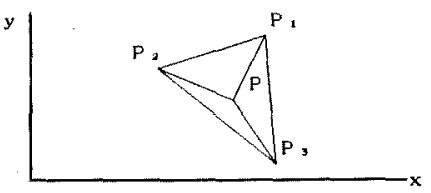

図 2 面積座標

Fig. 2. Area coordinate.

ただし

$$
J J^{*}=\omega^{2} \sigma^{2} Q Q^{*}+2 \sigma \omega\left(Q_{I} J_{S R}-Q_{R} J_{S I}\right)+J_{S} J_{s}^{*}
$$

ここに，Q:A- $\bar{A}, \bar{A}:$ 平均べクトルポテ ンシャル， $Q_{k}: Q$ の実数部， $Q_{1}: Q$ の虚数

部, $J_{S}$ : 印加電流, $J_{S R}: J_{S}$ の夷数部, $J_{S I}$ :

$J_{S}$ O虚数部， $\omega:$ 角周波数

である。また，要素内のポテンシャルAは，面積座 標 $\zeta_{1}, \zeta_{2}, \zeta_{3}$ と各頂点のポテンシャル $A_{1}, A_{2}, A_{3}$ を用い ると次式で表せる。

$$
A=\zeta_{1} A_{1}+\zeta_{2} A_{2}+\zeta_{3} A_{3}
$$

ただし，ここで用いた面積座標は図 2 のように，三角 形 $P_{1} P_{2} P_{3}$ を考えたとき, 点 $P$ を頂点とした三角形 $P P_{2} P_{3}, P P_{3} P_{1}, P P_{1} P_{2} の$ 面積を $\Delta_{1}, \Delta_{2}, \Delta_{3}$, 三角形 $P_{1}, P_{2}, P_{3}$ の面積を $\Delta$ とすると, 面積座標 $\zeta_{1}, \zeta_{2}, \zeta_{3}$ は 次式で定義される。

$$
\zeta_{1}=\frac{\Delta_{1}}{\Delta}, \quad \zeta_{2}=\frac{\Delta_{2}}{\Delta}, \quad \zeta_{3}=\frac{\Delta_{3}}{\Delta}
$$

（7）式と次式に示す積分公式を用いると, 導体の損失 は(10)式のようになる。

$$
\iint \zeta_{1}^{a} \zeta_{2}^{b} \zeta_{3}^{c} d S=2 \Delta \frac{a ! b ! c !}{(a+b+c+2) !} \cdots \cdots
$$

$こ こ に, \Delta:$ 要素の面積, $a, b, c: \zeta_{1}, \zeta_{2}, \zeta_{3}$ にかかる指数

$$
\begin{aligned}
W_{2}= & \frac{\Delta \omega^{2} \sigma}{2}\left(\left|A_{1}\right|^{2}+\left|A_{2}\right|^{2}+\left|A_{3}\right|^{2}\right. \\
& +A_{1 R} A_{2 R}+A_{1 I} A_{2 I}+A_{2 R} A_{3 R}+A_{2 I} A_{3 I} \\
& \left.+A_{3 R} A_{1 R}+A_{3 I} A_{1 I}\right) \\
& -\frac{\Delta \omega^{2} \sigma}{3}\left\{\left(A_{1 R}+A_{2 R}+A_{3 R}\right) \bar{A}_{R}\right. \\
& \left.+\left(A_{1 I}+A_{2 I}+A_{3 I}\right) \bar{A}_{I}\right\}+\frac{\Delta \omega^{2} \sigma}{2} \bar{A} \bar{A}^{*} \\
& +\frac{\Delta \omega}{3}\left\{\left(A_{1 I}+A_{2 I}+A_{3 I}-3 \bar{A}_{I}\right) J_{S R}\right. \\
& \left.-\left(A_{1 R}+A_{2 R}+A_{3 R}-3 \bar{A}_{R}\right) J_{S I}\right\} \\
& +\frac{\Delta}{2 \sigma} J_{S} J_{S}^{*} \ldots \ldots \ldots \ldots \ldots \ldots \ldots \ldots \ldots(10 \ldots \ldots \ldots \ldots
\end{aligned}
$$

ここに， $A_{i R}: A_{i}$ の赛数部, $A_{i \pi}: A_{i}$ の虚数

部, $\bar{A}_{R}: \bar{A}$ 実数部, $\bar{A}_{I}: \bar{A} \sigma$ 虚数部 
要素のエネルギー変化は磁界のエネルギー変化と導体 の損失の和で近似でき，次式のようになる。

$$
W=W_{1}+W_{2}
$$

〈2・2〉 節点の追加 節点の追加は, 線分の両側 の要素からなる四辺形のエネルギ一変化の值の大きい 領域から行う。ただし，境界上の線分で両側に要素か ない場合は，片側の要素のエネルギー変化の 2 倍の值 で比較を行う。

追加節点は次の二つのケースに分かれる。

（1）着目する線分が物体の輪郭または境界を表す 辺の一部

(2) (1) 以外

（1）の場合，節点は線分の中点に追加する。そして （2）の場合，節点は四辺形の重心に追加する。

〈2・3〉節点の刿除節点の削除はエネルギ一変 化の小さい要素から，要素の頂点の一つを辺に沿って
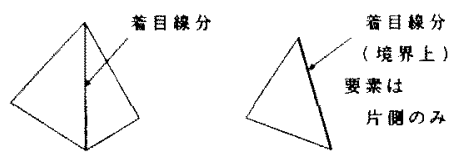

図3線分の両側の要素からなる四辺形 Fig. 3. Quadrangle consisting of two elements.

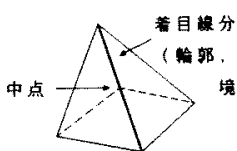

（1）の場合

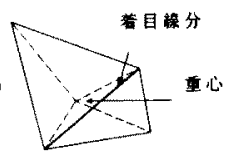

(2)の䏆合
図 4 節点の追加

Fig. 4. Additional node.

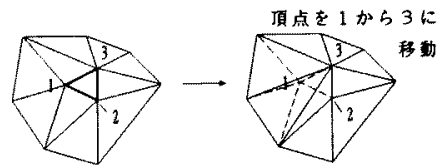

図 5 節点の削除

Fig. 5. Erased node.

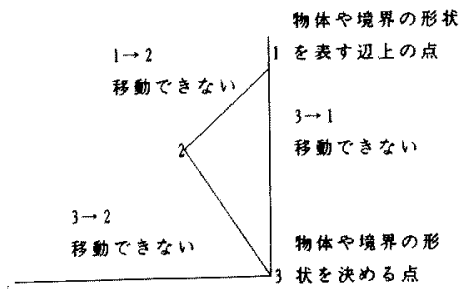

図 6 移動できない場合

Fig. 6. Unmovable case.
移動させることにより行う。

このとき，頂点の移動の仕方は 1-2，2-1，2-3，32，3-1，1-3 の六通りあるが，移動した後の領域の工 ネルギー変化が一番小さくなるものを選ぶようにす る。ただし，移動させる頂点が物体や境界の形状を决 める点のとき，または移動させる頂点が物体や境界の 形状を表す辺上にあり，移動先の頂点がその辺上にな いときは選択の対象から除く。

〈2・4〉終了条件 エネルギー均一化分割は節点 の追加, 削除の繰返しの過程において, 要素のエネル ギー変化の最大值が大きく変化しなくなったときに終 了する（例えば，変化率が 0.1 以下)。

\section{3. 表皮効果の考慮}

解析領域内に導体や磁性体が存在し，それらに渦電 流が流れる場合，それらの分割は表皮効果を考慮して 物体の表面を細かく分割する必要がある。

そこで，まず導体および磁性体の表面を表皮効果の 大きさを表す表皮厚に応じて縁どり，先に示したエネ ルギー均一化分割を行うことにより，表皮効果当考慮 した導体㧍よび磁性体の最適分割を行う。

〈3・1〉縁どり方法導体表面の縁どりは，図 7 に示すように表皮厚の 2 分の 1 の厚みで四層に縁ど る。このとき, 幾つかの物体の形状に対しては, 特に ルールを設けている。以下にその基本的なルールを示 寸。

（1）物体の厚みが薄く，各層の縁どりの段階で緑 どりができなくなる場合，表面の縁どりは一つ前の層 で終了する。

（2）自然境界で区切られた面は縁どりしない。

（3）物体の内部に空洞があり，その内外の両表面 を縁どったときに，それらが交わってしまう場合は縁 どりを結合する。



図 7 物体表面の緣どり

Fig. 7. Hemed surface.

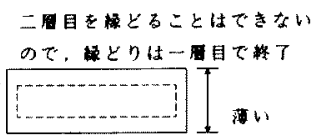

図 8 縁どりのルール 1

Fig. 8. Rule of hemming (No.1). 


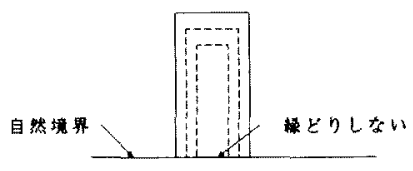

図 9 縁どりのルール 2

Fig. 9. Rule of hemming (No.2).
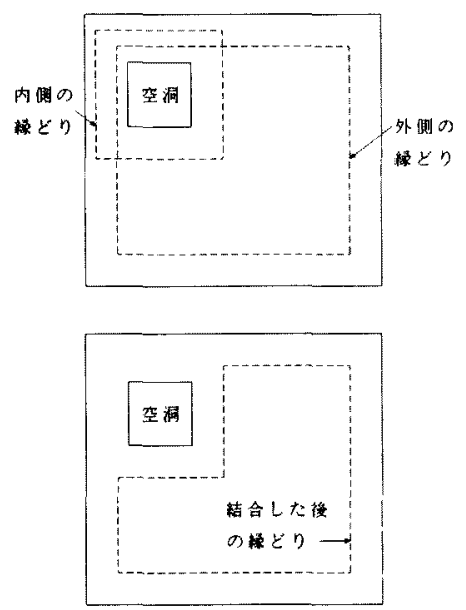

図 10 縁どりのルール 3

Fig. 10. Rule of hemming (No.3).

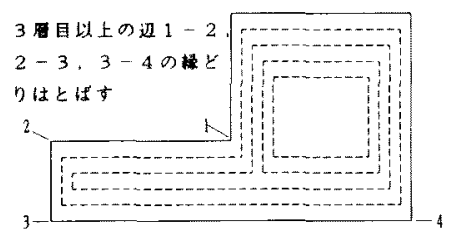

(a) 例 1

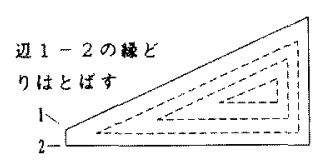

(b) 例 2

図 11 縁どりのルール 4

Fig. 11. Rule of hemming (No.4).

（4）物体の一部に（1）で示したような縁どる層の 厚みより薄くなる部分がある場合は，その部分をとば して緑どる。

\section{4, 偏平な要素の処理}

上記のように導体や磁性体の表面の縁どりを行う と，表皮効果の大きさによっては非常に偏平な要素が 導体表面に沿ってできる可能性がある。このような場

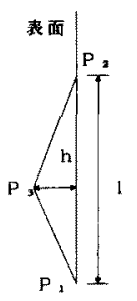

図 12 偏平な要素

Fig. 12. Flat element. Fig. 13. Additional node.

合，要素に対して適当な節点の追加を行う。

まず，要素の偏平度を次式のように決める。

要素の偏平度 $=\frac{h}{l}$

ここに，l:物体の表面に平行な辺の長さ，

$h: l$ 底辺とした高さ

また，要素のポテンシャルの変化の割合を次式のよう に決める。

要素のポテンシャルの変化の割合

$$
=\left(\left|A_{1}-A_{2}\right|\right) /\left(A_{H}-A_{L}\right)
$$

ここに， $A_{1}, A_{2}$ : 物体の表面に平行な辺の両 端 (図 $12, P_{1}, P_{2}$ ) のポテンシャル, $A_{H}$, $A_{L}$ : 物体の表面のポテンシャルの大きさの 最大値と鼠小值 そし,

要素の偏平度 $\leqq \varepsilon_{\mathbf{I}}$ 加

要素のポテンシャルの変化の割合 $\geqq \varepsilon_{2}$

$こ こ に, \varepsilon_{1}, \varepsilon_{2}:$ 任意の定数

のとき，節点を物体の表面に平行な辺の中点に追加す る(例えば, $\left.\varepsilon_{1}=0.1, \varepsilon_{2}=0.4^{(5)}\right) 。$

\section{5. 全体の処理の流れ}

本プログラムの処理手覑を以下に示す(図 14)。

（1）導体扮よび磁性体の表面の縁どり

(2) 解析領域の幾何学的な分割

(3) ポテンシャル計算

(4) エネルギー均一化分割

（5）導体肪よび磁性体の表面の偏平な要素の処理

\section{6. 誤差の検討}

本プログラムを無限平板の賣失解析（図 15 に電流 方向に垂直な断面図を示す）に適用し，その結果を理

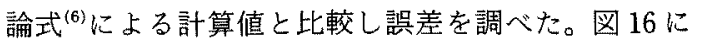
分割図の1例を示す。 


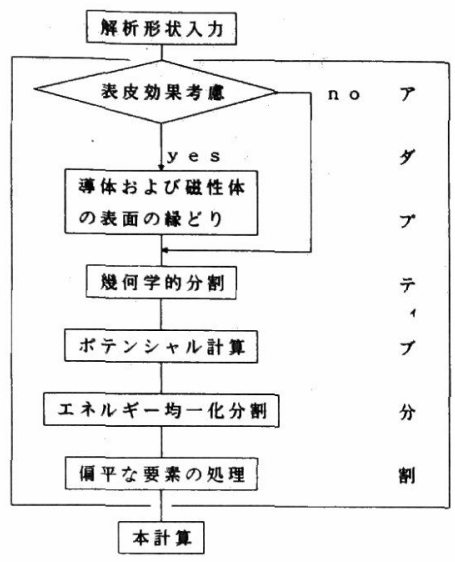

図 14 処理フロー

Fig. 14. Processing flow.

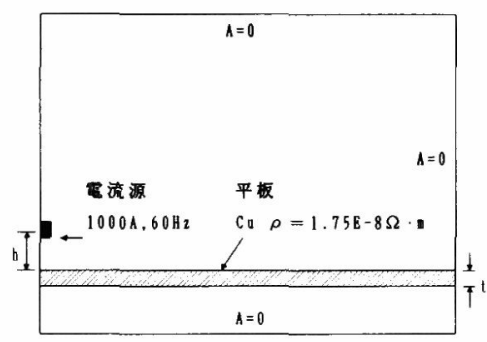

図 15 無限平板の解析モデル

Fig. 15. Analyzed model.

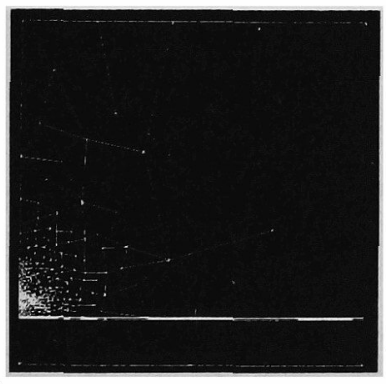

$\mathrm{h}=100 \mathrm{~mm}, \mathrm{t}=10 \mathrm{~mm}$

図 16 分割図

Fig. 16. Finite element mesh.

\section{〈6・1〉 電流源の位置の違いによる損失の変化}

電流源の平板からの距離 $(h)$ を変えたときの各損失 を, 平板の厚み $t=5 \mathrm{~mm}, 10 \mathrm{~mm}$ の 2 ケースで計算 し, 理論值と比較した。その結果, いずれの場合も誤 差は 5\%以内に収まった(図 17)。

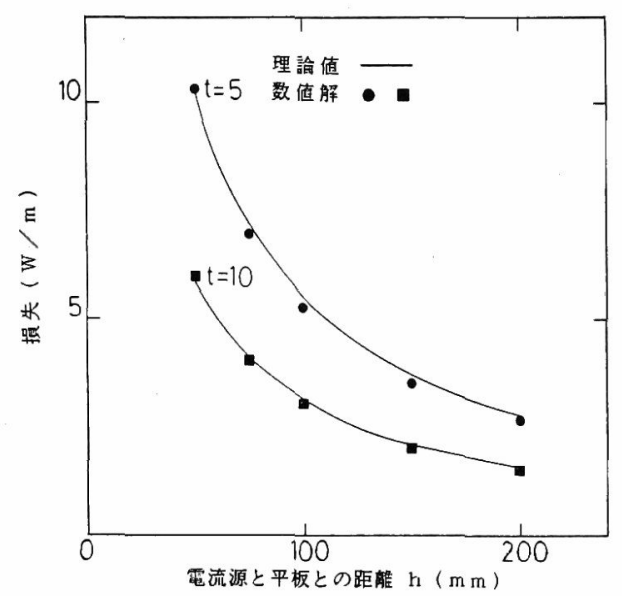

図 17 損失の変化

Fig. 17. Variation of loss.
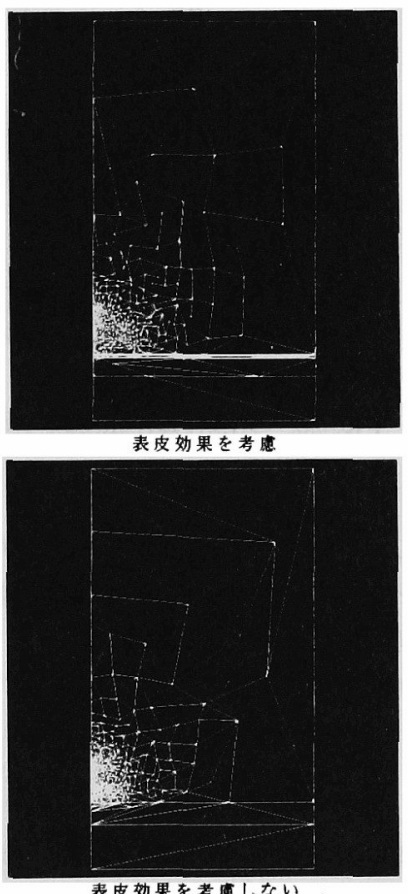

図 18 導体の分割

Fig. 18. Deviding of conductor.

〈6・2〉 周波数の違いによる損失誤差の変化

電流源の平板からの距離 $h=100 \mathrm{~mm}$, 平板の厚み $t=100 \mathrm{~mm}$ で周波数をパラメータとして各損失誤差 を求めた。また同時に, エネルギー均一化分割のみ （表皮効果を考慮しない分割）による各損失誤差も計 


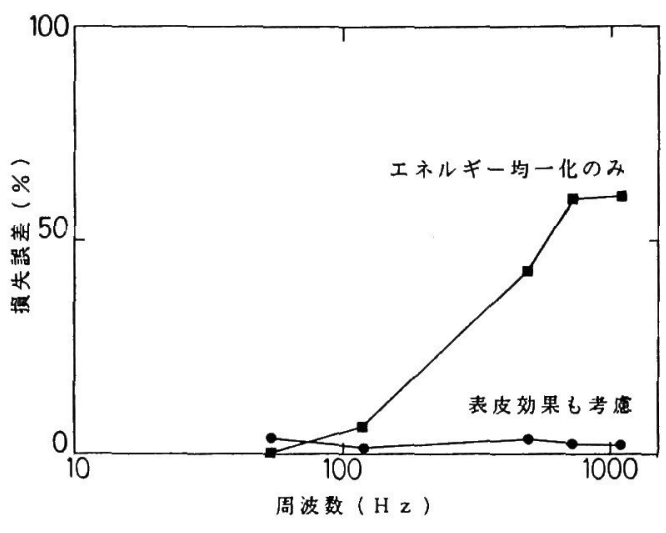

図 19 損失誤差の変化

Fig. 19. Variation of loss-error.

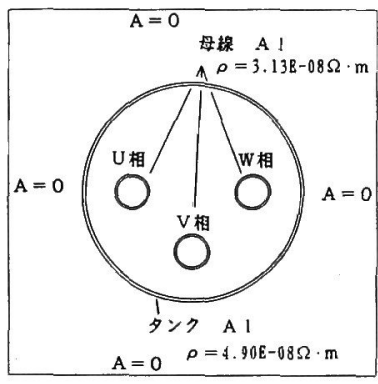

図 20 解析モデル

Fig. 20. Analyzed model.

算し比較した(分割の違いを図 18 に示す)。その結 果, エネルギー均一化分割のみでは周波数が高くな り，表皮効果が大きくなると誤差が大きくなっている が，表皮効果を考慮した本プログラムではいずれの場 合も詿差は 5\%以内に収まっている(図 19)。

\section{7. 適用 例}

ガス絶縁開閉装置などに用いられる三相一括母線 (図 20 に母線方向に垂直な断面図を示す) の電磁力解 析に本プログラムを適用した例を示す。

（1）三相短絡状態に抢ける母線間の電磁力解析を 行う場合の分割図（図 21）

（2）母線 $U, V$ が相間短絡したときの相間の電磁 力解析を行う場合の分割図 (図 22)

（3）タンクと母線 $U$ 相が一線地絡したときの夕 ンクと母線の電磁力解析を行う場合の分割図 (図 23)

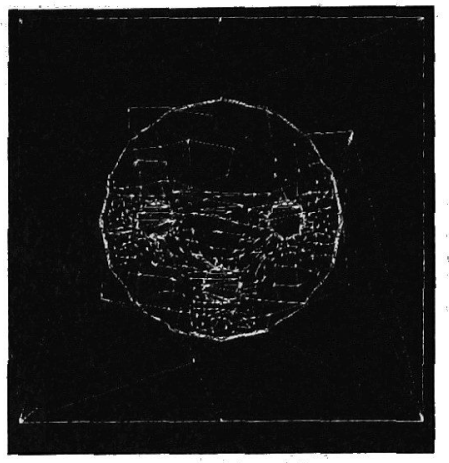

U相，V相，W相 $70 \mathrm{kA}$

図 21 分割図 1

Fig. 21. Finite element mesh (No. 1).

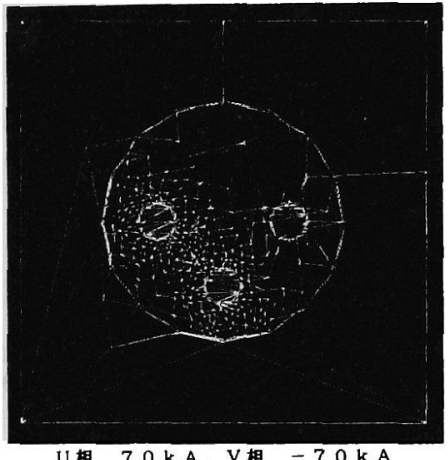

図 22 分割図 2

Fig. 22. Finite element mesh (No. 2).

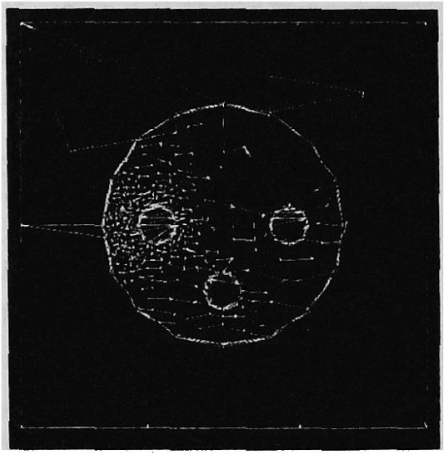

$\mathrm{U}$ 相 $70 \mathrm{kA}$. タンク $-70 \mathrm{kA}$

図 23 分割図 3

Fig. 23. Finite element mesh (No.3).

本プログラムでは，同じ三相一括母線の輪郭形状を 入力してもそれぞれの電磁現象に応じた分割を行うこ とができる。 


\section{8. むすび}

今回，開発したプログラムでは，エネルギー均一化 分割法に表皮効果を考慮した分割のノウハウを取入れ た。その結果, 導体や磁性体の渦電流による表皮効果 が大きくなるような解析に対しても妥当な分割を得る ことができた。また，本プログラムでは輪郭形状のみ の入力で電磁現象に応じた分割が行えるので，入力作 業を大幅に軽減できるようになった。

(平成元年 11 月 30 日受付, 同 2 年 8 月 20 日再受付)

\section{文献}

（1）中田・藤原・吉岡・金島：「二次元有限要素法のためのプリ・ポ ストシステムの開発」, 平元電気学会全大, No. 772

（2）山名·武·藤田：「有限要素解析における自動要素分割法」, 電気学会回転機·静止器合同研資, RM-82-47(昭 57)

（3）山名・武・藤田：「交番界有限要素法での最適自動分割法」, 昭 60 電気学会全大, No. 707

（4）斉藤・上田・小倉：「有限要素法のための磁界解析用アダプテ 1フフ分割法」, 平元同上, No. 770

（5）斉藤・上田・小倉：「有限要素法のためのアダプティブ分割法 一導体表面の自動分割一」, 平 2 同上, No. 805

(6) M. V. K. Chari: IEEE Trans. Power Apparatus Syst., PAS $-93.62(1974)$

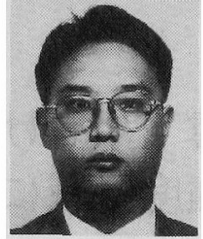

齋 藤 義 則 (正員)

昭和 38 年 10 月 24 日生。 62 年 3 月立命館大学理工学部卒業。同年 4 月三菱電機コントロールソフトウェ ア(株) 入社。主として, 電磁界解析 システムの開発に従事。

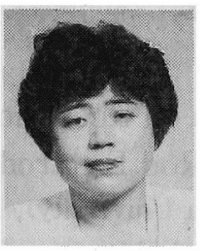

\section{上田泰子(非会員)}

昭和 34 年 1 月 23 日生。 56 年 3 月奈良女子大理工学部数学科卒業。 同年 4 月三菱電機(株) 入社。情報シ ステム部に所属。主として, CAE システムの環境整備および電磁界解析システムの開発 に従事。

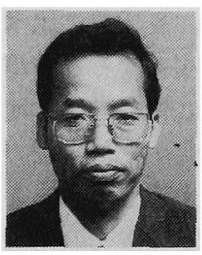

$$
\text { 小倉 新 三（正員） }
$$

昭和 18 年 11 月 23 日生。 37 年 3 月神戸工業高等学校電気科卒業。同 年 4 月三菱電機 (株) 入社。中央研究 所に勤務。 49 年 10 月以来伊丹製作 所に勤務。主として, 渦電流損などの磁界現象解析お よび開閉機器などの開発に従事。 